\title{
Low Temperature Catalytic Pyrolysis of Polyethylene Terephthalate
}

\author{
Surma, N*., Tor, P.N., and Ijuo, G.A. \\ Department of Chemistry, Federal University of Agriculture, Makurdi-Nigeria
}

*Corresponding Author: Surma, N, Department of Chemistry, Federal University of Agriculture, Makurdi-Nigeria

\begin{abstract}
Low temperature pyroylsis of polyethylene terepthalate (PET) was studied by adapting a pressure cooking pot of height $30.00 \mathrm{~cm}$ with an lnternal diameter of $31.50 \mathrm{~cm}$. The pyrolysis reaction was done using fluid catalytic cracking (FCC) catalyst. The gases evolved during the pyrolysis reaction were collected in tedlar bags and analysis was done using a Buck 530 gas chromatogram. The pyrolysis reaction with fresh fluid catalytic cracking (FCC) catalyst at $150^{\circ} \mathrm{C}$ and $250^{\circ} \mathrm{C}$ using catalyst / sample ratio of $1: 8$ showed aliphatic hydrocarbons in the range of $C_{1}-C_{10}$ with a total concentration of 485.8220 and 100.2732 ppm respectively. The corresponding values obtained at $150^{\circ} \mathrm{C}$ and $250^{\circ} \mathrm{C}$ using catalyst/sample ratio of 1:16 were 157.3500 and $84.1590 \mathrm{ppm}$ respectively. The pyrolysis reaction with spent $\mathrm{FCC}$ catalyst at $150^{\circ} \mathrm{C}$ and $250^{\circ} \mathrm{C}$ using catalyst/sample ratio of $1: 8$ gave the following total concentrations 91.6869 and 81.6393 ppm respectively. The corresponding values obtained at $150{ }^{\circ} \mathrm{C}$ and $250{ }^{\circ} \mathrm{C}$ using catalyst/sample ratio of 1:16 were 210.2899 and 123.7272 ppm respectively. Fuel gases, gasoline range products and other organic gases were obtained even when the reaction took place at lower temperatures thereby minimizing the cost of energy.
\end{abstract}

Keywords: Pyrolysis, Polyethylene terepthalate, Aliphatic hydrocarbon

\section{INTRODUCTION}

Plastics have become an indispensible part in today's world due to their light weight, durability, and energy efficiency. Coupled with a faster rate of production and design flexibility these plastic are employed in the entire gamut of industrial and domestic areas, hence plastics have become essential materials and their application in the industrial field continually increasing [1,2,3,4]. As a result of this contribution a large amount of plastic waste is generated due to increase in its production and usage each year. This increase in the amount of waste does cause some environmental challenges since plastics do not degrade quickly and can remain in the environment for a long time [5] a large part of this waste ends up in landfills or is incinerated [6,7].

These waste plastics being bulkier than other organic residues occupy massive space in landfills and therefore the proper disposal and incineration require high cost. Further incineration of these waste plastics results in environmental problems due to increased emission of harmful compounds [5]. Therefore it is necessary for more sustainable solutions than incineration and disposal in landfills which has prompted a number of research works, thus, much research in the area of recycling and reuse of these post- consumed polymers have been carried out in order to produce raw materials and energy[7,8].

The various types of recycling methods are good options to control the increase of plastic waste, because they are environmentally friendly when compared to incineration and disposal in landfills. With pyrolysis which is one of the recycling methods, it is possible to recover raw materials, energy and fuel and when these products and energy are recovered, the environmental impact of industrial activity is reduced [5]. It is against this it is against this background that this work was aimed at producing useful gases via low temperature pyrolysis using fresh and spent FCC catalyst

\section{Materials AND Methods}

\subsection{Collection and Preservation of Materials}

The polyethylene terepthalate (PET) waste which consisted of containers used in packaging drinking water were collected from refuse dumping sites around Makurdi town, Benue State of Nigeria. The 
samples were washed thoroughly using detergent and rinsed properly with de-ionized water, then dried to remove moisture content. The dry samples were the reduced to smaller to bits increase the surface area. The fluid catalytic cracking (FCC) catalyst employed for this work was obtained from Nigerian National Petroleum Cooperation (NNPC) Warri in Delta state and is shown by analysis to be composed of aluminium and silicon, scanning electron microscopy (SEM) images of the fresh FCC catalyst were obtained at magnifications of $1000 \mathrm{x}, 2500 \mathrm{x}, 5000 \mathrm{x}, 10000 \mathrm{x}$, and $15000 \mathrm{x}$ respectively. Scanning electron microscopy (SEM) images of the spent FCC catalyst were obtained at magnification of 500x, $1000 x, 2150$ x, 5000x, and 10000x. From the SEM images it was deduced that the catalyst particle range within $5 \mu \mathrm{m}-80 \mu \mathrm{m}$ while the spent FCC catalyst gave particle sizes within the range of $8 \mu \mathrm{m}$ $100 \mu \mathrm{m}$. In further characterizing the fresh and spent FCC catalyst, SEM was combined with atomic absorption spectrometry (AAS) in the detection of the metal composition. Analysis indicated the presence of aluminium (5.122 and $3.375 \mathrm{ppm}$ ) and silicon (6.480 and 5.270 ppm) respectively.

\subsection{Expe rimental Procedure}

A pressure pot made of stainless steel (with dimensions of height $30 \mathrm{~cm}$ and internal diameter of 31.5 $\mathrm{cm}$ ) was adapted for the reaction. The cover had an outlet tube at the top for collection of the evolved gases. The reactor fitted in the sand bath was heated with three mekker burners in order to attain the required temperature which was controlled by means of a thermocouple. Tedlar bags were used for collection of the evolved gases which were sent to a gas chromatogram for analysis.

\subsection{Catalytic Cracking of PET}

Two catalyst/sample ratios (1:8 and 1:16) were investigated in the catalyzed pyrolysis. The sample (polymer material $200 \mathrm{~g}$ ) was placed at the bottom while the catalyst material was arranged in sandwich layers within the polymer sample [9]. The reactor was covered and heating commenced. After 30 minutes into the reaction evolution of gases started slightly and this was evident as the tedlar bag began to swell. After heating for about $1_{1 / 2}$ hours at $250^{\circ} \mathrm{C}$, the system was shut down. The gases which were collected at $150^{\circ} \mathrm{C}$ and $250^{\circ} \mathrm{C}$ in labeled tedlar bags were analyzed. The system was shut down, allowed to cool before the reactor was opened. The residue for each run was collected and weighed.

\subsection{Gas Chromatography Analysis}

The gaseous products obtained from pyrolysis of PET with the effect of both fresh and spent FCC catalyst were characterized using a Buck 530 gas chromatography with HP-88 $(10 \mathrm{~m} / 0.25 \mathrm{~mm}$ thickness). Injection volume was $10 \mu \mathrm{L}$ with helium as the mobile phase and flame ionization detector (FID), injection and detection temperatures were $250{ }^{\circ} \mathrm{C}$ and $280{ }^{\circ} \mathrm{C}$ respectively.

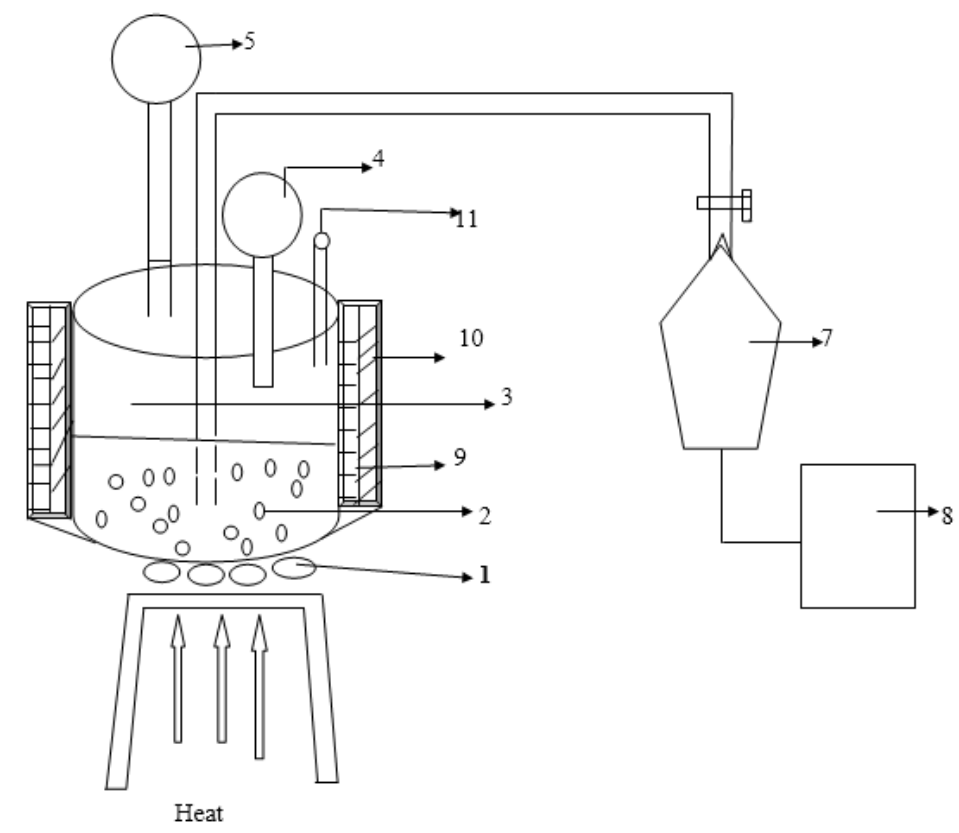

Fig1. Layout of the pyrolysis process

1.Heating mantle, 2.Waste material/ catalyst, 3.Reactor, 4.Pressure, 5.Thermocouple, 6.Regulator 7.Tedlar gas sampling long beg, 8.G.C Analyzer, 9.Lagging material, 10.Sand bath,11.Stopered inlet 


\section{RESULTS AND DISCUSSION}

The polyethylene terepthalate employed for this work were containers used in packaging drinking water. The weights obtained at the end of the catalytic pyrolysis as residue were $110 \mathrm{~g}$ and $105 \mathrm{~g}$ using catalyst/sample ratio of 1:8 and 1:16 respectively with the fresh FCC catalyst. The catalytic pyrolysis with the spent FCC catalyst gave residues with the following weights $110 \mathrm{~g}$ and $120 \mathrm{~g}$ using catalyst/sample ratio of 1:8 and 1:16 respectively comparative composition of gases evolved from pyrolysis of waste PET using fresh FCC catalyst at $150{ }^{\circ} \mathrm{C}$ and $250{ }^{\circ} \mathrm{C}$ using catalyst/sample ratios of 1:8 and 1:16 is presented in Tables 1 and 2 while the results obtained from the reaction using spent FCC catalyst at $150{ }^{\circ} \mathrm{C}$ and $250{ }^{\circ} \mathrm{C}$ using catalyst/sample ratios of 1:8 and 1:16 is presented in Tables 3 and 4 respectively.

Detailed chemical mechanism for the conversion of polyethylene to lower molecular weight hydrocarbons is still a matter of conjecture. Loss of hydrogen atom followed by homolytic $\beta$ - fission of a $\mathrm{C}-\mathrm{C}$ bond could be a plausible path way [10]. When the polymer feed contacts the catalyst in the reaction, the degradation is proceeding in two steps. During the first step, the polymer is vaporized by the hot surface of the catalyst. The second step contains formation of positively charged carbon ions, so called carbocation [11].

\subsection{Results}

Table1. Results of gas chromatographic analysis obtained by reaction with sample and fresh FCC catalyst catalyst/sample ratio of 1:18 after heating for one and a half hours

\begin{tabular}{|l|l|l|l|}
\hline Component & Organic Compound & Reaction at $150{ }^{\circ} \mathrm{C}$ & Reaction at $250{ }^{\circ} \mathrm{C}$ \\
\cline { 2 - 4 } & & Concentration $(\mathbf{p p m})$ & Concentration $(\mathbf{p p m})$ \\
\hline $\mathrm{C}_{1}$ & n- Methane & 67.9703 & 8.8882 \\
\hline $\mathrm{C}_{2}$ & n- Ethane & 107.6425 & 25.0552 \\
\hline $\mathrm{C}_{3}$ & 38.2143 & 15.1556 \\
\hline $\mathrm{C}_{4}$ & n- Propane & Nil & 5.0942 \\
\hline $\mathrm{C}_{5}$ & n- Butane & 29.2805 & Nil \\
\hline $\mathrm{C}_{6}$ & n- pentane & Nil & 2.8184 \\
\hline $\mathrm{C}_{7}$ & n- Hexane & 69.4263 & 19.2924 \\
\hline $\mathrm{C}_{8}$ & n- Heptane & 140.6575 & 16.9002 \\
\hline $\mathrm{C}_{9}$ & n-Octane & 31.9925 & 14.0739 \\
\hline Total & n- Nonane & $\mathbf{4 8 5 . 2 8 8 8}$ & $\mathbf{1 0 0 . 2 7 3 2}$ \\
\hline
\end{tabular}

Table2. Composition of gases obtained from pyrolysis of PET at $150^{\circ} \mathrm{C}$ and $250^{\circ} \mathrm{C}$ with fresh FCC catalyst using catalyst/ sample ratio of 1:16 after heating for one and a half hours.

\begin{tabular}{|l|l|l|l|}
\hline \multirow{2}{*}{ Component } & Organic Compound & Reaction at $150^{\circ} \mathrm{C}$ & Reaction at $250^{\circ}{ }^{\circ} \mathrm{C}$ \\
\cline { 3 - 4 } & & Concentration $\mathbf{( p p m})$ & Concentration $(\mathbf{p p m})$ \\
\hline $\mathrm{C}_{1}$ & n- Methane & 2.8056 & 2.3316 \\
\hline $\mathrm{C}_{2}$ & n- Ethane & 24.0545 & 17.3443 \\
\hline $\mathrm{C}_{3}$ & n- Propane & 33.8352 & 10.7448 \\
\hline $\mathrm{C}_{4}$ & n- Butane & 5.1263 & 4.9593 \\
\hline $\mathrm{C}_{5}$ & n- pentane & Nil & Nil \\
\hline $\mathrm{C}_{6}$ & n- Hexane & 7.2071 & 2.7469 \\
\hline $\mathrm{C}_{7}$ & n- Heptane & 19.2184 & 15.3374 \\
\hline $\mathrm{C}_{8}$ & n-Octane & 30.1053 & 16.8040 \\
\hline $\mathrm{C}_{9}$ & n- Nonane & 34.9977 & 13.8907 \\
\hline Total & & $\mathbf{1 5 7 . 3 5 0 0}$ & $\mathbf{8 4 . 1 5 9 0}$ \\
\hline
\end{tabular}

Table3. Composition of gases obtained from pyrolysis of PET at $150{ }^{\circ} \mathrm{C}$ and $250^{\circ} \mathrm{C}$ with spent FCC catalyst using catalyst/sample ratio of 1:8 after heading for one and a half hours

\begin{tabular}{|l|l|l|l|}
\hline Component & Organic Compound & Reaction at $150{ }^{\circ} \mathrm{C}$ & Reaction at $250{ }^{\circ} \mathrm{C}$ \\
\cline { 3 - 4 } & & Concentration $(\mathbf{p p m})$ & Concentration $(\mathbf{p p m})$ \\
\hline $\mathrm{C}_{1}$ & n-Methane & 1.1559 & 0.8096 \\
\hline $\mathrm{C}_{2}$ & n- Ethane & 0.0200 & 0.0102 \\
\hline $\mathrm{C}_{3}$ & n- Propane & 2.6958 & 3.1515 \\
\hline $\mathrm{C}_{4}$ & n- - Butane & 3.9200 & Nil \\
\hline $\mathrm{C}_{5}$ & n-pentane & 32.2516 & 47.1888 \\
\hline
\end{tabular}




\begin{tabular}{|l|l|l|l|}
\hline $\mathrm{C}_{6}$ & n-Hexane & 0.0063 & 0.0033 \\
\hline $\mathrm{C}_{7}$ & n- Heptane & 11.5949 & 5.0052 \\
\hline $\mathrm{C}_{8}$ & n-Octane & 8.2681 & 6.2397 \\
\hline $\mathrm{C}_{9}$ & n- Nonane & 31.8043 & 19.2311 \\
\hline Total & & $\mathbf{9 1 . 6 8 6 9}$ & $\mathbf{8 1 . 6 3 9 3}$ \\
\hline
\end{tabular}

Table4. Composition of gases obtained from pyrolysis of PET at $150^{\circ} \mathrm{C}$ and $250^{\circ} \mathrm{C}$ with spent FCC catalyst using catalyst/sample ratio of 1:16 after heating for one and a half hours

\begin{tabular}{|l|l|l|l|}
\hline Component & Organic Compound & Reaction at $150{ }^{0} \mathrm{C}$ & Reaction at $250{ }^{0} \mathrm{C}$ \\
\cline { 3 - 4 } & & Concentration (ppm) & Concentration (ppm) \\
\hline $\mathrm{C}_{1}$ & n- Methane & 51.1925 & 12.8517 \\
\hline $\mathrm{C}_{2}$ & n- Ethane & Nil & 0.0099 \\
\hline $\mathrm{C}_{3}$ & 14.7425 & 1.1012 \\
\hline $\mathrm{C}_{4}$ & n- Propane & 7.2789 & Nil \\
\hline $\mathrm{C}_{5}$ & n- Butane & 104.8903 & 78.5391 \\
\hline $\mathrm{C}_{6}$ & n- pentane & 0.0014 & 0.0060 \\
\hline $\mathrm{C}_{7}$ & n- Hexane & 5.6614 & 7.4093 \\
\hline $\mathrm{C}_{8}$ & n- Heptane & 22.4618 & 23.8100 \\
\hline $\mathrm{C}_{9}$ & n-Octane & 4.0612 & Nil \\
\hline Total & n- Nonane & $\mathbf{2 1 0 . 2 8 9 9}$ & $\mathbf{1 2 3 . 7 2 7 3}$ \\
\hline
\end{tabular}

Polyethylene terepthalate wastes were pyrolysed at $150{ }^{\circ} \mathrm{C}$ and $250{ }^{\circ} \mathrm{C}$ using catalyst/ sample ratio of 1:8 and the result of the gas chromagtographic analysis is presented in Table 1 above. The results show that the total concentration of gaseous component obtained was $485.2888 \mathrm{ppm}$ and $100.2732 \mathrm{ppm}$ at $150{ }^{\circ} \mathrm{C}$ and $250{ }^{\circ} \mathrm{C}$ respectively for the reaction which occurred using catalyst/ sample ratio of $1: 8$. The same reaction performed under the same conditions of temperature $\left(150{ }^{\circ} \mathrm{C}\right.$ and $\left.250{ }^{\circ} \mathrm{C}\right)$ using catalyst/sample ratio of 1:16 showed that the total gaseous composition were $157.3500 \mathrm{ppm}$ and $84.1590 \mathrm{ppm}$ respectively, the results are presented in Table 2 .

From these results it is obvious that the effect of product yield was more pronounced at lower temperatures. However, the reaction was more enhanced by increase in amount of catalyst as the total concentrations obtained by using catalyst/ sample ratio of 1:8 was higher than the total concentration obtained when the pyrolysis reaction was done using catalyst/sample ratio of 1:16. This agrees with the fact that conversion increases with increase in catalyst loading [12].

The pyrolysis reaction that occurred using catalyst/ sample ratio of 1:8 gave the most dominant components in $\mathrm{C}_{2}$ (107.6424 ppm), $\mathrm{C}_{3}(38.2143 \mathrm{ppm}), \mathrm{C}_{7}(69.4263 \mathrm{ppm})$ and $\mathrm{C}_{8}(140.6575 \mathrm{ppm}) . \mathrm{C}_{4}$ carbon atoms were not identified among the gases collected at $150{ }^{\circ} \mathrm{C}$. On the other hand, the dominant components observed from analysis of gases collected at $250{ }^{\circ} \mathrm{C}$ were $\mathrm{C}_{2}(25.0552 \mathrm{ppm})$ and $\mathrm{C}_{7}(19.2424$ $\mathrm{ppm})$ here, $\mathrm{C}_{5}$ carbon atom was not identified from the gases. In every case the most dominant component was observed in $\mathrm{C}_{2}$. This could be explained with the structure and degradation pattern of polyethylene because it is built from $\mathrm{C}_{2}$ monomers [13].

It is a general observation that the FCC catalyst results in more gasoline range products. This could be attributed to the bi modal pore size distribution and mild acidic properties of the FCCs which allows the formation of more paraffin [13]. This was evident in the results as the carbon atoms within the range of $\mathrm{C}_{5}-\mathrm{C}_{9}$ were obtained reasonably after the catalytic pyrolysis with the fresh FCC catalyst.

The fresh FCC catalyst was expected to show diminishing activity during the pyrolysis reaction since coke formation is a common problem with the FCC catalyst

In petroleum and polyolefin pyrolysis research [14]. From the pyrolysis reaction with PET using catalyst/sample ratio of 1:8 presented in Table 1 above, the concentration of gases dropped with increase in temperature from (485.2888 to $100.2732 \mathrm{ppm}$ ), similarly with catalyst/sample ratio of $1: 16$ as presented in Table 2 above, the values decreased from (157.3500 to $84.1590 \mathrm{ppm}$ ). This could have been as a result of the deactivation of the fresh FCC catalyst as it is usually the trend.

Polyethylene terepthalate (PET) waste materials were pyrolysed with spent FCC catalyst at $150{ }^{\circ} \mathrm{C}$ and $250{ }^{\circ} \mathrm{C}$ using catalyst/sample ratio of $1: 8$ and the result is shown in Table 3 above. From the result of the gas chromatographic analysis, the total concentration of gases at $150{ }^{\circ} \mathrm{C}$ yielded $91.6889 \mathrm{ppm}$ and that collected at $250{ }^{\circ} \mathrm{C}$ gave $81.6393 \mathrm{ppm}$, it is obvious from the results that the concentration of the 
product is more pronounce at lower temperatures that at higher temperatures. This is an indication that the spent FCC catalyst though regenerated lead to faster cracking of the PET thereby leading to smaller residence time [5]. With FCC catalyst in pyrolysis reactions the activity of the catalyst is expected to drop with increase in coke yield, this could have been the reason for the drop in the total concentration of the gaseous products in the reaction at $250{ }^{\circ} \mathrm{C}$ [14].

The pyrolysis reaction that occurred using catalyst/sample ratio of 1:8 gave the most dominant component in $\mathrm{C}_{5}(32.2516 \mathrm{ppm}), \mathrm{C}_{7}(5.0052 \mathrm{ppm}), \mathrm{C}_{8}(6.2397 \mathrm{ppm})$ and $\mathrm{C}_{9}(19.2311 \mathrm{ppm})$. This indicates that the gases in the gasoline range were dominant which is a general trend with reactions involving FCC catalysts [14]. The result of pyrolysis of PET materials using catalyst/sample ratio of 1:16 as presented in Table 4 gave total concentrations of gases at $150{ }^{\circ} \mathrm{C}$ and $250{ }^{\circ} \mathrm{C}$ to be 210.2899 ppm and $123.7273 \mathrm{ppm}$ respectively. The highest components from the results were observed in $\mathrm{C}_{1}$ (12.8517 ppm), $\mathrm{C}_{5}(78.5391 \mathrm{ppm}), \mathrm{C}_{7}(7.4093 \mathrm{ppm})$ and $\mathrm{C}_{8}(238100 \mathrm{ppm})$. Again, it is observed that the dominant components were within the gasoline range products $\left(\mathrm{C}_{5}-\mathrm{C}_{9}\right)$ which are a generalobservation with the FCC catalyst [15].

Generally the spent FCC catalysts are expected to show diminishing activity which was evident from the results as the total gas concentrations were lower with the spent FCC catalyst than the total concentrations with the fresh FCC catalyst. However, there were still significantly effective in the pyrolysis reaction as the spent FCC catalyst was able to show high cracking activity yielding gasoline range products. Also, the gas concentration showed a decrease which could be attributed to the formation of coke entrapped in the pure of the catalyst [16]

\section{CONCLUSion}

The consumption of plastics has increased over the years and the concern with their waste generated too. Waste plastics release gas emission into the environment when incinerated because plastic are non biodegradable their waste can remain for a long period in landfills. In this work the thermo-catalytic pyrolysis of contaminated polyethylene terepthalate (PET) was studied. If was observed that the total gas concentration was higher with the reaction done with fresh FCC catalyst when the gases were collected at a lower temperature $150{ }^{\circ} \mathrm{C}$ although with increased catalyst loading. The pyrolysis reaction has been effective because the gas concentration was enhanced by both fresh and spent FCC catalyst. Useful gases within gasoline range were recovered as well as fuel gases within the $C_{1}-C_{4}$ range even though the reaction occurred at relatively low temperature thereby minimizing the energy cost.

\section{REFERENCES}

[1] Xiangxiu, Z,, Jie, A., Yuzhough, W.(2012): Process of producing vehicle fuel from cracking waste plastics. Chemical Industry and Engineering Progress. 31,: 359-407

[2] Zheng, D.M., LU, Q.F., Liu,M., and Chen Y. X. (2011):Study of catalytic cracking of waste plastics and waste lubricating oils for producing fuel oil. Modern Chemical Industry 31 (8): 47 - 49

[3] Choa, W. , Xiaobo, M., and Hai, W. (2013): Studies on effective thermal conductivity coefficient of plastic waste pyrolysis process Materials Review. 27 (5): 108 - 111

[4] Abbas - Abadi, M.S., Haghghi, M.N., and Yeganeh, H. (2013): Evaluation of pyrolysis products of virgin high density polylethylene degradation using different process parameters in a stirred reactor. Fuel Processing Technology. 109: $90-92$

[5] Almeida, D., and Margues, M.F. (2015): Thermal and catalytic pyrolysis of plastic waste. Polimeros 26 (1): 1- 8 http;//dxdoi. org/10.1590/0104 - 1428. 2100

[6] Stelmachwski, M. (2010) Thermal conversion of waste polyolefins to the mixture by hydrocarbon in the reactor with molten metal bed. Conversion and Management 51 (10): 2016 - 2020 http://dx.doi.Org /10.101b/j.enconman. 2010 .02.035

[7] Miskolczi, N., and Nagy, R. (2012): Hydrocarbons obtained by waste plastic pyrolysis; Comparative analysis of decomposition described by different kinetic models. Fuel Processing and Technology. 104: 96 - 104 http://dx, doi org/ 10. 1010/j. fuproc . 2012. 04.031

[8] Arabiourrutia, M., Elordi, G., Lopez, G., Borsella, E., Bilbao., J. and Olazar, M. (2012): Characterizeation of waxes obtained by the pyrolysis of polyolefin plastics in a conical spouted bed reactor. Journal of Analytical and Applied Pyrolysis. 94:230 - 237 http://dx.doi.org/10.1016/j.jaap.2011. 12012

[9] Abdulkareem, S.A., Eleburuike, N.A., and Amoloye, T.O. (2014): comparison of fuel oil from thermal and catalytic cracking of high density polyethylene. J. Chem.Soc . Nigeria 39(1):103 - 106

[10] Nwadinigwe, C.A. (2012) Basic principles of organic chemistry (2012): WIPRO International. pp101. 
[11] Abbot, J., and Wojciechowski, B.W. (1987) Transfer reactions in the catalytic cracking of paraffins. Journal of Catalysis, 107: 451

[12] Aguado , J., Serrano, D.P., and Gomez, A. (2001) : Influence of the operating variables on the catalytic conversion of polyolefin mixture over HCM-41 and a Nanosized HZSM - 5. Industrial and Engineering Chemical Research. 40 (24): 5659 - 5704

[13] Borsidi, N., Miskolczi, N., Angyal, A., Bartha, L., Kohan, J., and lengyel, A. (2011): Hydrocarbons obtained by pyrolysis of contaminated waste plastics. $4^{\text {th }}$ International Petroleum Conference Bratrislava Slovak Republic Pp $1-9$

[14] Lee, K.H., and Shin, O. H. (2003): Catalytic degradation of waste HDPE over acidic catalyst with different pore sizes. Journal of Industrial and Engineering Chemistry 9 (5): 584 - 589

[15] Bagri, R., and Williams, R.T. (2002): Catalytic pyrolysis of polyethylene, Journal of Analytic and Applied Pyrolysis 63 (1):29 - 41

[16] Manos, G. A., Garforth, A., and Dwyer, J. (2000): Catalytic degradation of high density polyethylene over different zeolite structures. Industrial and Engineering Chemistry Research 35 (5):1198 - 1202.

Citation: N. Surma et al., "Low Temperature Catalytic Pyrolysis of Polyethylene Terephthalate", International Journal of Advanced Research in Chemical Science (IJARCS), vol. 5, no. 5, pp. 20-25, 2018. http://dx.doi.org/10.20431/2349-0403.0505005

Copyright: (C) 2018 Authors. This is an open-access article distributed under the terms of the Creative Commons Attribution License, which permits unrestricted use, distribution, and reproduction in any medium, provided the original author and source are credited. 